\title{
An Appraisal of Clients' Utilization of National Health Insurance Scheme (NHIS) Services at the Kubwa General Hospital
}

\author{
Marvel Osalugwe Ehiosun \\ Institute of Public Administartions and Extension Services, University of Benin \\ ehiosunmarvel@gmail.com
}

Keywords: NHIS, dissatisfaction, client, enrollee

\begin{abstract}
NHIS was launched officially on 6th of June 2005. The Scheme is designed to provide comprehensive health care at affordable costs, covering employees of the formal sector, selfemployed, as well as rural communities, the poor and the vulnerable groups. However, client satisfaction of services rendered continues to be a major concern for the improvement of NHIS. This study is designed to determine the level and causes of dissatisfaction of clients accessing NHIS clinic at the Kubwa General Hospital, Kubwa, FCT, Abuja. This study employed a descriptive cross sectional survey. 279 NHIS enrollees were recruited for this study at the Kubwa General Hospital. Questionnaires were administered and the level of dissatisfaction and satisfaction of NHIS services were analyzed. The satisfaction rate was $69.2 \%$ while the dissatisfaction rate was $22.9 \%$. The respondents were satisfied with the attitude of health workers in NHIS clinic, Kubwa. However, they were dissatisfied with waiting time, attitude of record officers and those in pharmacy department. This study found that the level of dissatisfaction with NHIS services is high despite a high satisfaction level. The Attitude of health workers may influence the dissatisfaction of enrollees. NHIS is still limited to the formal sector.
\end{abstract}

\section{Introduction}

The National Health Insurance Scheme (NHIS) was launched in Nigerian on October 15, 1997 and was passed into law in May 1999 [4]. However, the conception of NHIS dates back to 1962 when the need for financing health care for Nigerians was first recognized [1]. The Federal Government approved NHIS in 1997, signed it into law in 1999 and officially on the 6th June 2005 [9]. The original scheme has been modified to accommodate the less privileged persons in the Nigeria [4].

The Scheme is designed to provide comprehensive health care delivery at affordable costs, covering employees of the formal sector, self-employed, as well as rural communities, the poor and the vulnerable groups [14]. The need for the establishment of the scheme was informed by the general poor state of healthcare services in the country, excessive dependence and pressure on the government's provision of health facilities, dwindling funding of health care in the face of rising cost, poor integration of private health facilities in the nation's healthcare delivery system and overwhelming dependence on out-of-pocket expenses to purchase health [5].

Like any other insurance scheme, the premium for the NHIS is the amount charged by the insurance compared with the promise to pay for any eventual covered medical treatment for the designated coverage. Consequently, health insurance makes it possible to substitute a small but certain cost for a larger but uncertain loss (chain) under an arrangement in which the healthy majority compensate for the risks and costs of the unfortunate ill minority. The NHIS currently represents $15 \%$ of one's basic salary. The employer is to pay $10 \%$ while the employee contributes $5 \%$ of his/her basic salary to enjoy healthcare benefits. The contribution made by the insured person entitles his/her spouse and four children under the age of 18 to full health benefits [5].

NHIS was designed to provide minimum economic security for workers with regard to unfavorable losses resulting from accidental injury, sickness, old age, unemployment and premature death of family wage earner. NHIS is made compulsory because the government based on past experiences predicted that some citizens cannot engage in the scheme and the government also has 
the duty to protect the general welfare of all citizens [6]. It is also the government's belief that NHIS will help to break the vicious cycle of poverty in the country. It is also a form of social support for workers [8].

The rationale for establishment of NHIS is very robust at reducing the burden of financing healthcare service. Despite this robust nature of NHIS, the health care demand is still very high. This bothers around the operations of NHIS and level of satisfaction of clients utilizing the NHIS services. Identified factors responsible for lack of satisfaction of NHIS services include shortage of drugs and out of stock syndrome, unavailability of blood and essential consumables, prolong waiting time which many refer to as waste of precious time, poor attitude of staff to work and unnecessary protocol. NHIS had earlier been implemented to target the formal sector which amount to less than $20 \%$ of the total population of Nigeria. It is expected that NHIS will be at its peak in delivering effective and quality services due to its small target population. However, this has not been the experience of Nigerians enrolled under NHIS as many still prefer to visit hospitals where services received will be paid for out of pocket (OOP).

Although, there are few reports on the effectiveness of NHIS and client satisfaction, such data are lacking in Federal Capital Territory (FCT), Abuja. Therefore, this study intends to determine the dissatisfaction of clients enrolled under NHIS and their experiences of the scheme at the General Hospital in Kubwa, Federal Capital Territory (FCT), Abuja. Results from this study is expected to awaken policy makers to fulfilling the objectives of NHIS, help to improve the logistics, service delivery and staff attitude towards clients.

\section{Methodology}

\subsection{Type of Study/ Study Setting/ Population}

This study is a descriptive cross sectional survey. The setting for this study was NHIS clinic in Kubwa General Hospital, Bwari Area, Federal Capital Territory Abuja. The Hospital is a secondary health facility with over 200 bed capacity. It is a major referral Centre to neighboring General Hospital and Primary Health Centers. It is one of the hospitals within the Federal Capital Development Authority.

The population for this study were all enrollees of NHIS above eighteen years (18) in Kubwa General Hospital, Kubwa, Abuja, having been enrolled for a period of six months and above, and have visited the NHIS clinic to access care.

\subsection{Sampling}

Simple random sampling using a lucky dip method was used to select study subjects. Only enrollees visiting the NHIS clinic on a clinic day had a probability of being selected. Sample size estimation was calculated using the formula derived from Leslie-Kish formula $\left(\mathrm{n}=\mathrm{Za} \mathrm{a}^{2} \mathrm{pq} / \mathrm{d}^{2}\right)$ for descriptive studies and using $26 \%$ as the proportion of enrollees who were dissatisfied with NHIS in a previous survey [13]. Calculated sample size is 295.6, thus, 300 enrollees will be sampled.

\subsection{Subjects}

The subjects for this study were all those enrolled under NHIS and were visiting the NHIS clinic to receive health care.

\subsection{Data Analysis}

Data was analysed using Statistical Package for Social Sciences (SPSS) version 16. The Likerts scale was used to assess the degree of agreement and disagreement with statements in the questionnaires. Chi-Square was used to assess the relationship between the variables of dissatisfaction and socio-demographic parameters.

\subsection{Ethical considerations}

Ethical clearance was obtained from the ethical committee of the Kubwa General Hospital, Kubwa, FCT, Abuja. The participants recruited for this study were informed of the purpose, 
procedure, risk and the importance of the research. They were asked to freely make a decision to participate in the study or not, and that there would be no form of discrimination or intimidation meted against them if unwilling to participate. Those willing to participate were asked to fill an informed consent form and sign. The ideas and views gotten from literature is acknowledged by referencing.

\section{Results}

\subsection{Socio Demographic Characteristics of the Respondents}

Table 1 is a composition of the socio-demographic characteristics of respondents for the study. About $77.8 \%$ of the respondents were in the age range of $35-64$ years while $22.2 \%$ were in the in the age range of 15-34years.

Table 1. Socio-Demographic Characteristics of NHIS Registered Respondents in Kubwa General Hospital, Kubwa, FCT, Abuja

\begin{tabular}{|c|c|c|c|}
\hline \multicolumn{2}{|c|}{ Socio-Demographic Characteristics } & Numbers of Respondents & Percentage $(\%)$ \\
\hline \multirow{5}{*}{ Age } & $15-24$ & 12 & 4.3 \\
\hline & $25-34$ & 50 & 24.2 \\
\hline & $35-44$ & 102 & 36.6 \\
\hline & $45-54$ & 83 & 29.7 \\
\hline & $55-64$ & 32 & 11.5 \\
\hline \multirow{2}{*}{ Gender } & Male & 142 & 50.9 \\
\hline & Female & 137 & 49.1 \\
\hline \multirow{3}{*}{ Educational Level } & Primary School & 5 & 1.8 \\
\hline & Secondary School & 95 & 34.1 \\
\hline & Tertiary Institution & 179 & 64.2 \\
\hline \multirow{2}{*}{ NHIS Status } & Dependent & 84 & 30.1 \\
\hline & Principal & 195 & 69.9 \\
\hline \multirow{4}{*}{ Employment Status } & Government & 222 & 79.6 \\
\hline & Private & 13 & 4.7 \\
\hline & Self Employed & 22 & 7.9 \\
\hline & Dependent & 22 & 7.9 \\
\hline \multirow[t]{3}{*}{ Marital Status } & Single & 61 & 21.9 \\
\hline & Married & 218 & 78.1 \\
\hline & Separated & 0 & 0 \\
\hline \multirow{2}{*}{ Family Type } & Monogamy & 265 & 95 \\
\hline & Polygamy & 14 & 5 \\
\hline \multirow{2}{*}{ Family Size } & Equal/Below Six & 204 & 73.1 \\
\hline & Above 6 & 75 & 26.9 \\
\hline \multirow{4}{*}{$\begin{array}{l}\text { Numbers of Years } \\
\text { spent in NHIS }\end{array}$} & 1 & 18 & 6.5 \\
\hline & $2-3$ & 26 & 9.3 \\
\hline & $3-5$ & 110 & 39.4 \\
\hline & $>5$ & 125 & 44.8 \\
\hline
\end{tabular}

\subsection{Acceptance of NHIS Concept}

Table 2 shows the level of acceptance of the NHIS concept among registered clients in the facilities. 
Table 2. The level of acceptance of the NHIS concept among registered clients in the facilities

\begin{tabular}{|c|c|c|}
\hline Responses & Frequency (n) & Percentage (\%) \\
\hline Undecided & 12 & 4.3 \\
\hline Disagree & 0 & 0 \\
\hline Agree & 172 & 61.6 \\
\hline Strongly Agree & 95 & 34.1 \\
\hline Total & 279 & 100 \\
\hline $\mathrm{X}^{2}=1.377, \mathrm{df}=3, \mathrm{p}<0.05$ &
\end{tabular}

$\mathrm{X}^{2}=1.377, \mathrm{df}=3, \mathrm{p}<0.05$

Out of the 279 respondents, $12(4.3 \%)$ of the respondents were undecided about the concept of NHIS, none $(0 \%)$ disagree with the concept of NHIS, $172(61.6 \%)$ of the respondents agree with the concept of NHIS while $95(34.1 \%)$ of the respondents strongly agree with the concept of NHIS. There was a significant statistical difference $(p<0.05)$ in acceptance of NHIS concept among respondents accessing NHIS in Kubwa General Hospital, Kubwa, FCT, Abuja.

\subsection{Satisfaction with NHIS Services}

Table 3 shows the level of satisfaction with NHIS services among registered clients in the facilities.

Table 3. The level of satisfaction with NHIS services among registered clients in the facilities

\begin{tabular}{|c|c|c|}
\hline Responses & Frequency (n) & Percentage (\%) \\
\hline Undecided & 22 & 7.9 \\
\hline Unsatisfied & 64 & 22.9 \\
\hline Satisfied & 156 & 55.9 \\
\hline Very Satisfied & 37 & 13.3 \\
\hline Total & 279 & 100 \\
\hline $\mathrm{X}^{2}=33.90, \mathrm{df}=3, \mathrm{p}<0.05$
\end{tabular}

$22(7.9 \%)$ of the respondents were undecided about their satisfaction with NHIS services, 64 $(22.9 \%)$ of the respondents were unsatisfied with NHIS services, $156(55.9 \%)$ of the respondents were satisfied with NHIS services while $37(13.3 \%)$ of the respondents were very satisfied with NHIS services. There was significant statistical difference $(p<0.05)$ in satisfaction of NHIS among respondents accessing NHIS in Kubwa General Hospital, Kubwa, FCT, Abuja.

\subsection{Assessment of NHIS clinic service}

Table 4 shows the response of respondent to their assessment of NHIS clinic service.

Table 4. The response of respondent to their assessment of NHIS clinic service

\begin{tabular}{|c|c|c|}
\hline Responses & Frequency (n) & Percentage (\%) \\
\hline Below Expectation & 43 & 15.4 \\
\hline Substandard & 24 & 8.6 \\
\hline Standard & 177 & 63.4 \\
\hline Quality & 35 & 12.5 \\
\hline Total & 279 & 100 \\
\hline $\mathrm{X}^{2}=2.225, \mathrm{df}=3, \mathrm{p}<0.05$ & &
\end{tabular}

Among the respondents, $43(15.4 \%)$ of the respondents rated the treatment received in NHIS clinic as below expectation, $24(8.6 \%)$ of the respondents rated the treatment received in NHIS clinic as substandard, $177(63.4 \%)$ of the respondents rated the treatment received in NHIS clinic as standard while $35(12.5 \%)$ of the respondents rated the treatment received in NHIS clinic as quality. there was significant statistical difference $(p<0.05)$ in the rating of treatment received in NHIS clinic among respondents accessing NHIS clinic in Kubwa General Hospital, Kubwa, FCT, Abuja. 


\subsection{Preference for NHIS}

Presented in Table 5 is the response of respondents to know if given other alternatives, would they still prefer to access NHIS services.

Table 5. The response of respondents

\begin{tabular}{|c|c|c|}
\hline Responses & Frequency & Percentage (\%) \\
\hline Never & 0 & 0 \\
\hline Maybe & 140 & 50.7 \\
\hline Definitely Yes & 136 & 49.3 \\
\hline Total & 276 & 100 \\
\hline $\mathrm{X}^{2}=0.058, \mathrm{df}=2, \mathrm{p}<0.05$ & Non Respondents $=3$
\end{tabular}

$0(0 \%)$ of the respondents would never prefer to access NHIS services if given other alternatives, 140 (50.7\%) of the respondents would maybe prefer to access NHIS services if given other alternatives while $136(49.3 \%)$ of the respondents would definitely prefer to access NHIS services if given other alternatives. There was significant statistical difference $(p<0.05)$ in preference for NHIS when given other alternatives among respondents accessing NHIS clinic in Kubwa General Hospital, Kubwa, FCT, Abuja.

\subsection{Comfortability with Billing System}

Table 6 shows the response of respondent to how confortable are they to the billing system.

Table 6. The response of respondent to how comfortable are they to the billing system

\begin{tabular}{|c|c|c|}
\hline Responses & Frequency & Percentage (\%) \\
\hline Undecided & 2 & 0.7 \\
\hline Not Comfortable & 130 & 46.9 \\
\hline Very Comfortable & 145 & 52.4 \\
\hline Total & 277 & 100 \\
\hline $\mathrm{X}^{2}=2.016, \mathrm{df}=2, \mathrm{p}<0.05$ & \multicolumn{2}{|c|}{ Non-Respondents $=2$}
\end{tabular}

The Table 6 equally shows that $2(0.7 \%)$ of the respondents were undecided about how comfortable they were with the billing system, $130(46.9 \%)$ of the respondents were not comfortable with the billing system while $145(52.4 \%)$ of the respondents were very comfortable with the billing system. there was significant statistical difference $(p<0.05)$ on how comfortable the billing system was among respondents accessing NHIS clinic in Kubwa General Hospital, Kubwa, FCT, Abuja.

\subsection{Waiting Time in NHIS Clinic}

Presented in Table 7 is the response to know how much time they spend in NHIS clinic (waiting time).

Table 7. The response to know how much time they spend in NHIS clinic (waiting time)

\begin{tabular}{|c|c|c|}
\hline Responses & Frequency (n) & Percentage (\%) \\
\hline Less than 1 Hour & 109 & 39.1 \\
\hline 1-2 Hours & 10 & 3.6 \\
\hline 2-3hours & 22 & 7.9 \\
\hline 3-4hours & 138 & 59.4 \\
\hline Total & 279 & 100 \\
\hline $\mathrm{X}^{2}=2.669$, df: $2, \mathrm{p}>0.05$ & &
\end{tabular}

$$
\mathrm{X}^{2}=2.669 \text {, df: } 2, \mathrm{p}>0.05
$$

$109(39.1 \%)$ of the respondents spends less than an hour in NHIS clinic, $10(3.6 \%)$ of the respondents spends between 1-2 hours in NHIS clinic, $22(7.9 \%)$ of the respondents spends between 2-3 hours in NHIS clinic while 138 (59.4\%) of the respondents spends between 3-4 hours in NHIS 
clinic $\left(X^{2}=2.669\right)$. There was no significant statistical difference $(p>0.05)$ on total time spent in NHIS clinic among respondents accessing NHIS in Kubwa General Hospital, Kubwa, FCT, Abuja.

\subsection{Area of NHIS with most Waiting Time}

Presented in Table 8 is the response to know how which area of NHIS do they spend longer time.

Table 8. The response to know how which area of NHIS do they spend longer time

\begin{tabular}{|c|c|c|}
\hline Responses & Frequency (n) & Percentage (\%) \\
\hline Medical Records & 16 & 5.8 \\
\hline Nurses Stations & 17 & 6.2 \\
\hline Consulting Room & 216 & 78.3 \\
\hline Laboratory & 27 & 9.8 \\
\hline Total & 276 & 100 \\
\hline $\mathrm{X}^{2}=4.186, \mathrm{df}=3, \mathrm{p}<0.05$ & \multicolumn{2}{|c|}{ Non-Respondents $=3$} \\
\hline
\end{tabular}

$16(5.8 \%)$ of the respondents spends most time in records department, $17(6.2 \%)$ of the respondents spends most time in Nurses stations, $216(78.3 \%)$ of the respondents spends most time in consulting room while $27(9.8 \%)$ of the respondents spends most time in laboratory $\left(\mathrm{X}^{2}=4.186\right)$. There was a significant statistical difference $(p<0.05)$ on area where most time is spent in NHIS clinic among respondents accessing NHIS in Kubwa General Hospital, Kubwa, FCT, Abuja.

\subsection{Attitude of Staff in NHIS Clinic}

Presented in Table 9 is the response to how satisfied the respondents were to the attitude of staffs in NHIS clinic.

Table 9. The response to how satisfied the respondents were to the attitude of staffs in NHIS clinic

\begin{tabular}{|c|c|c|}
\hline Responses & Frequency (n) & Percentage (\%) \\
\hline Undecided & 2 & 0.7 \\
\hline Unsatisfied & 21 & 7.8 \\
\hline Satisfied & 205 & 76.5 \\
\hline Very Satisfied & 40 & 14.9 \\
\hline Total & 268 & 100 \\
\hline $\mathrm{X}^{2}=3.898, \mathrm{df}=3, \mathrm{p}<0.05$ & Non-Respondents $=11$
\end{tabular}

$2(0.7 \%)$ of the respondents were undecided about how pleased they are with the attitude of staff in NHIS clinic, $21(7.8 \%)$ of the respondents were unsatisfied with the attitude of staff in NHIS clinic, $205(76.5 \%)$ of the respondents were satisfied with the attitude of staff in NHIS clinic while $40(14.9 \%)$ of the respondents were very satisfied with the attitude of staff in NHIS clinic. There was significant statistical difference $(p<0.05)$ on area where most time is spent in NHIS clinic among respondents accessing NHIS in Kubwa General Hospital, Kubwa, FCT, Abuja.

\subsection{Health Professional pleased with}

Presented in Table 10 is the response to know the health professionals the respondents are pleased with.

Table 10. The response to know the health professionals the respondents are pleased with

\begin{tabular}{|c|c|c|}
\hline Responses & Frequency (n) & Percentage (\%) \\
\hline Doctors & 170 & 79.1 \\
\hline All Workers & 17 & 7.9 \\
\hline Records & 26 & 12.1 \\
\hline Laboratory & 2 & 0.9 \\
\hline Total & 215 & 100 \\
\hline $\mathrm{X}^{2}=340.70, \mathrm{df}=3, \mathrm{p}<0.05$ & Non-Respondents $=64$
\end{tabular}


$170(79.1 \%)$ of the respondents were satisfied with the attitude of doctors in NHIS clinic, 17 (7.9\%) of the respondents were pleased with attitude of all the workers in NHIS clinic, 26 (12.1\%) of the respondents were pleased with the attitude of medical record officers in NHIS clinic while 2 $(0.9 \%)$ of the respondents were pleased with the attitude of laboratory personnel in NHIS clinic. There was significant statistical difference $(\mathrm{p}<0.05)$ on health personnel pleased with in NHIS clinic among respondents accessing NHIS clinic Kubwa General Hospital, Kubwa, FCT, Abuja.

\subsection{Health Professionals not pleased with}

Presented in Table 11 is the response to know the health professionals the respondents are not pleased with.

Table 11. The response to know the health professionals the respondents are not pleased with

\begin{tabular}{|c|c|c|}
\hline Responses & Frequency (n) & Percentage (\%) \\
\hline Records & 50 & 48.5 \\
\hline Nurses Stations & 7 & 6.8 \\
\hline Laboratory & 14 & 13.6 \\
\hline Pharmacy & 27 & 26.2 \\
\hline Radiology & 5 & 4.9 \\
\hline Total & 103 & 100 \\
\hline $\mathrm{X}^{2}=66.854, \mathrm{df}=4, \mathrm{p}<0.05$ & Non-Respondents $=176$
\end{tabular}

The Table 11 shows that $50(48.5 \%)$ of the respondents were not pleased with the attitude of record staffs in NHIS clinic, $7(6.8 \%)$ of the respondents were not pleased with the attitude of Nurse staffs in NHIS clinic, $14(13.6 \%)$ of the respondents were not pleased with the attitude of laboratory staffs in NHIS clinic, $27(26.2 \%)$ of the respondents were not pleased with the attitude of pharmacy staffs in NHIS clinic while $5(4.9 \%)$ of the respondents were not pleased with the attitude of radiology staffs in NHIS clinic. There was significant statistical difference $(p<0.05)$ on health professionals not pleased with in NHIS clinic among respondents accessing NHIS in Kubwa General Hospital, Kubwa, FCT, Abuja.

\subsection{Sustainability of NHIS}

Presented in Table 12 is the response of respondents to the sustainability of NHIS.

Table 12. The response of respondents to the sustainability of NHIS

\begin{tabular}{|c|c|c|}
\hline Responses & Frequency (n) & Percentage (\%) \\
\hline Probably & 24 & 8.7 \\
\hline Maybe & 8 & 2.9 \\
\hline Yes & 244 & 88.4 \\
\hline Total & 276 & 100 \\
\hline $\mathrm{X}^{2}=5.958, \mathrm{df}=2, \mathrm{p}<0.05 \quad$ Non-Respondent $=3$
\end{tabular}

Table 12 shows that $24(8.7 \%)$ of the respondents said probably they would want NHIS to be sustained, $8(2.9 \%)$ of the respondents said maybe they would want NHIS to be sustained while 244 $(88.4 \%)$ of the respondents said yes they would want NHIS to be sustained. There was significant statistical difference $(p<0.05)$ on response to sustainability of NHIS among respondents accessing NHIS in Kubwa General Hospital, Kubwa, FCT, Abuja.

\subsection{Areas for Improvement in NHIS}

Presented in Table 13 is the response of respondents to the area of NHIS that they want improvement. 
Table 13. The response of respondents to the area of NHIS that they want improvement

\begin{tabular}{|c|c|c|}
\hline Responses & Frequency (n) & Percentage (\%) \\
\hline Waiting Time & 129 & 48.9 \\
\hline Pharmacy & 85 & 32.2 \\
\hline Laboratory & 39 & 14.8 \\
\hline Billing System & 11 & 4.2 \\
\hline Total & 264 & 100 \\
\hline
\end{tabular}

$$
\mathrm{X}^{2}=122.48, \mathrm{df}=3, \mathrm{p}<0.05 \quad \text { Non-Respondent }=15
$$

$129(48.9 \%)$ of the respondents wants improvement in the waiting time in NHIS clinic, 85 (32.2\%) of the respondents wants improvement in pharmacy and out of stock syndrome, $39(14.8 \%)$ of the respondents wants improvement in laboratory while $11(4.2 \%)$ of the respondents wants improvement in the billing system. There was significant statistical difference $(p<0.05)$ on area of improvement in NHIS among respondents accessing NHIS in Kubwa General Hospital, Kubwa, FCT, Abuja.

\subsection{Factors Influencing Dissatisfaction}

Presented in Table 14 are the responses of respondents to factors influencing the level of dissatisfaction.

Table 14. The responses of respondents to factors influencing the level of dissatisfaction

\begin{tabular}{|c|c|c|c|c|c|}
\hline Factors & & $\begin{array}{l}\text { Sum of } \\
\text { Squares }\end{array}$ & df & $\begin{array}{l}\text { Mean } \\
\text { Square }\end{array}$ & $\mathrm{F}$ \\
\hline \multirow[t]{3}{*}{ Gender } & Between Groups & 11.136 & 12 & 0.928 & 15.591 \\
\hline & Within Groups & 2.500 & 42 & 0.060 & \\
\hline & Total & 13.636 & 54 & & \\
\hline \multirow[t]{3}{*}{ Age } & Between Groups & 41.427 & 12 & 3.452 & 19.862 \\
\hline & Within Groups & 7.300 & 42 & 0.174 & \\
\hline & Total & 48.727 & 54 & & \\
\hline \multirow[t]{3}{*}{ Duration in NHIS } & Between Groups & 25.382 & 12 & 2.115 & 22.209 \\
\hline & Within Groups & 4.000 & 42 & 0.095 & \\
\hline & Total & 29.382 & 54 & & \\
\hline \multirow{3}{*}{$\begin{array}{c}\text { Prolong Waiting } \\
\text { Time }\end{array}$} & Between Groups & 218.213 & 12 & 18.184 & 48.602 \\
\hline & Within Groups & 15.714 & 42 & 0.374 & \\
\hline & Total & 233.927 & 54 & & \\
\hline \multirow[t]{3}{*}{ NHIS Facility } & Between Groups & 65.922 & 12 & 5.494 & 40.377 \\
\hline & Within Groups & 5.714 & 42 & 0.136 & \\
\hline & Total & 71.636 & 54 & & \\
\hline \multirow[t]{3}{*}{ Staff Attitude } & Between Groups & 30.681 & 12 & 2.557 & 9.396 \\
\hline & Within Groups & 11.429 & 42 & 0.272 & \\
\hline & Total & 42.109 & 54 & & \\
\hline
\end{tabular}

\section{Discussion of the Results}

This study shows that NHIS covers all age group which is in line with the objectives of NHIS. It also shows that NHIS is mostly accessed by those in the working age of 25-65years who serves majorly as the primary enrolees. This also suggest that the NHIS clinic in Kubwa General Hospital 
has its operations in tandem with the goals of NHIS to provide health insurance to both the insured and their dependents evidenced by the distribution of enrolee status. This study observed that the formal sector still form the bulk of the enrolees under NHIS reflected by a high percentage $(84.3 \%)$ of government and private company workers.

Shaffiu [15] also reported a similar finding in his study in Jos, Nigeria. The initial plan of NHIS was to kick start the program with the formal sector in the year 2005 and then extend it to the informal sector. The majority of our population belong to the informal sector and reflect Nigeria's health indices which are used globally. They include the artisans, traders, transport workers, market women, and farmers. However, it is still surprising that these groups of citizens within the informal sector are yet to benefit from nation's health insurance policy. An earlier study by Akeem et al. [2] in Lagos, Nigeria to determine the reactions of artisans in the state to NHIS implementation observed that these groups of citizens feel neglected and marginalized. It is a matter of urgency to look into the expansion of the NHIS to accommodate more people irrespective of their employment status in order to improve on the current poor health indices of the nation.

Both genders patronize NHIS scheme without disparity. The number of male respondents was more than their female counterparts in this study; usually more females attend clinics than males. Although, this is not significant, it might be a reflection of the high tertiary level of education observed among the respondents and a positive health orientation. Also, this may be due to a more pleasant experience in NHIS clinic that made the male folks to seek health care.

There is a greater number of people with tertiary education attending NHIS clinic in Kubwa General Hospital, this is a reflection of high literacy level of city dwellers and the impact their level of education have on their health seeking behaviour irrespective of the gender status. The table also shows that the higher the level of education, the greater the acceptance of NHIS. This observation supports earlier reports by Kayode et al. [10] in a study carried out in Ibadan that those with tertiary education were more satisfied with NHIS in the areas of drug availability and healthcare provider services.

It was observed that most people utilizing the NHIS are Government or Civil Servants who are as a result of government compulsion of NHIS on military and paramilitary group and also making allowance for state health insurance scheme covering state government workers.

This study found that NHIS clinic is majorly accessed by married people who will thereby increasing the level of registration as the principal will also register it immediate family as dependants. Also, it was found that the family type practiced in Kubwa, FCT, Abuja is monogamy. This is also typical of westernization and education which is expected of a civilized environment. Furthermore, a greater percentage (73.1) of respondents has a family size of six and below while $26 \%$ of the respondents have a family size of above 6 reflective of a civilized environment.

Most people registered during the inception of NHIS as lesser registrations are occurring from $44 \%$ to $6 \%$ and most of the respondent have spent above 5 years in NHIS. Kayode et al. [10] reported that clients with longer duration of enrolment were more satisfied with waiting time and staff attitude which is the case in $\mathrm{KGH}$.

This study shows that most respondents accept the concept of NHIS which is as a result of the provision of quality health service by NHIS than other health facilities. Moreover, majority of enrolees $(94.4 \%)$ have a good perspective of NHIS with adequate knowledge of its operations. However, some enrolees still demonstrate inadequate understanding of the financial commitments towards NHIS. This is in line with a study conducted in Jos, Nigeria, the clients accessing the NHIS are satisfied with scheme and a similar report from a study carried out in Ibadan, undulating nature of satisfaction was observed.

This study found that many enrolees of NHIS in KGH are satisfied with the services rendered. About $69.2 \%$ of respondents were satisfied while $22.9 \%$ were dissatisfied with NHIS services in $\mathrm{KGH}$. Shaffiu [15] reported a similar satisfaction rate of $61.5 \%$ and dissatisfaction rate of $26 \%$. This finding is also supported by earlier reports by Iloh et al. [7] who recorded an overall satisfaction rate of $66.8 \%$ in his study in south-eastern Nigeria. In Addition, Onyedibe et al. [13] reported that $61.5 \%$ were satisfied with NHIS services while $26 \%$ were dissatisfied. However, Kayode et al. [10] 
reported an undulating level of satisfaction with NHIS services depending on the component under examination. Therefore, this shows that most of the respondents are satisfied with NHIS services but the number $(22.9 \%)$ of the respondent that are unsatisfied is still significant and warrant necessary action. This number may increase if separate components of NHIS services are examined suggesting a need for thorough service evaluation and assessment.

It was also observed that NHIS services in KGH are assessed as standard enough by $63.4 \%$ of respondents and as quality by $12.5 \%$ of the respondents. This suggests that the KGH is operating at a capacity similar to that of a teaching hospital. However, a significant minority would regard the services as below expectation $(15.4 \%)$. This assessment by these respondents might be due to other factors relating to treatment and not necessarily the treatment given which could have influenced their evaluation. This is supported by Blanchet et al [3] who reported that quality of NHIS services is influenced by patient perception of different component such as health care provider relationship or availability of drugs. In his report, Kayode et al. [10] also found out that ineffectiveness and inefficiency in certain areas of operation of the scheme undoubtedly depicts poor quality of services from the patients' perspective.

Most of the respondents (52.4\%) are very comfortable with the billing system of NHIS. There is a monthly contributory fund from both employer and employee and a $10 \%$ fees charge for drugs while most investigations are free. This eases off the burden of 'out of pocket payment' which could be difficult at times especially for salary earners. However, about $46.9 \%$ of respondents are uncomfortable with the billing of NHIS. This could be due to the fact that some enrolees have recurrent experience with the out of stock syndrome in the pharmacy due to frequent unavailability of drugs. Many of the enrolees are displeased with this and as such feel cheated as they are not benefiting from their contribution. This is because many people would want to have value for their money which they expect to be tangible.

Tables 7 and 8 both show that most of the respondents have a waiting time of about 3-4 hours in NHIS clinic with most of the time spent waiting to be called into consulting room. This is probably due to few doctors available in generally in Nigeria. There had been reports that Doctor to Patient ration in Nigeria is $1: 53,333$. There is also the problem of brain drain whereby many doctors move to Westernized countries for greener pasture further reducing the pool of doctors available. Furthermore, NHIS clinic utilize the medical officers within the domicile hospital on rotation to NHIS clinic so that these doctors have other clinical roles outside the NHIS clinic.

Generally, the respondents were satisfied with the attitude of the health personnel in the NHIS clinic. The respondents were mostly $(79.1 \%)$ satisfied with the doctors followed by medical record officers (12.1\%). This finding is similar to previous reports by Iloh et al. [7] and Ofili [12]. However, many (48.5\%) of the respondents are dissatisfied with the attitude of record officers in NHIS clinic, KGH followed by personnel in pharmacy department. This perception of respondents might be due to the fact that the records department is usually their first point of contact for those attending clinic and usually the last point of contact. As such, there is frequent contact between enrolee and the staff in medical records department. Medical records handle a lot of patient information and data including registration, retrieval and filing of patient folders, archiving of important documents, generation of approval codes for investigations and referrals, stamping of prescription forms, authorization of referral forms and liaison between enrolee and the HMOs among other functions. Thus, the number of personnel is usually fewer to the numerous administrative roles required of such workers. Therefore, there is usually friction between the enrolee and the officers. The medical records form an integral component of NHIS and would require necessary attention and equipping along with periodic staff performance evaluation and training.

The number on non-respondents to questions requiring the enrolees to comment on the group of professionals displeased is low compared to those who responded to it. This might be due to a generation perception in our environment which does not support a negative comment on staff especially in a public setup. It is generally believed that such comment can lead to termination of such employees. Therefore, clients will rather keep mute than give a contrary opinion regarding 
wrong attitude of public servants. This may also suggest the basis of gross indiscipline and impunity with our government setup. However, if we desire an improvement in our public services, there must be a healthy criticism from the users of such services. Therefore, this is of a great importance to future research areas.

This study shows that about $88.4 \%$ of the respondents would want NHIS to be sustained, however, with an improvement of its services particularly in the areas of waiting time and availability of drugs. This is in line with the findings of Onyedibe et al. [13] who reported unsatisfactory experiences of enrolees in the scheme; these include inadequate drug supplies, poor prescriptions of drugs poor registration services, poor referral system and delays in receiving required services. Therefore, it can be said that the domains of client satisfaction of NHIS services is largely based on staff attitude, availability of drugs and prolong waiting time. These areas form the basis for improvement of NHIS services and their predictors.

\section{Conclusion}

The conclusion regarding this study can only be generalized to Kubwa General Hospital, Kubwa, FCT, Abuja. The quantitative result revealed that the health workers in secondary health facility have more Knowledge, Attitude and Practice toward IDSR than the health workers in primary health facility. The results also show that Clients attending NHIS clinic are satisfied with the services rendered in Kubwa General Hospital, Kubwa, FCT, Abuja. This is as a result of the provision of quality health services in the NHIS clinic and the satisfactory attitude of the health workers in the clinics. The result also shows that prolong waiting time is not a cause of dissatisfaction among clients attending NHIS clinic in Kubwa General Hospital, Kubwa, FCT, Abuja. However, the major reasons for dissatisfaction are unavailability of drugs, billing system and records.

\section{Conflict of Interest}

The author declares that there is no conflict of interest.

\section{References}

[1] T.M. Akande, O. Bello, National Health Insurance Scheme in Nigeria, Medilor J. 7(1) (2002) 21-26.

[2] A.A. Akeem, S. Adedoyin, O. Olasunmbo, Artisan reactions to National Health Insurance Scheme in Lagos State, Nigeria, 2011.

[3] N.J. Blanchet, G. Fink, I. Osei-Akoto, The effect of Ghana's National Health Insurance Scheme on health care utilization, Ghana Med J. 46(2) (2012) 76-84.

[4] Nigerian Federal Ministry of Health Abuja FMH. The National Health Policy and strategy to Achieve Health for all. FMH, Abuja, 1998.

[5] Nigerian Federal Ministry of Health Abuja Operational Guideline of National Health Insurance, 2005.

[6] A. Ibiwoye, A.A. Adeleke, The impact of health insurance on healthcare provision in developing countries, Ghananian J. Development Stud. 4(21) (2007) 49-58.

[7] G.U.P. Iloh et al., Evaluation of patients' satisfaction with quality of care provided at the National Health Insurance Scheme clinic of a tertiary hospital in South- Eastern Nigeria, Nigerian Journal of Clinical Practice. 15(4) (2012) 469-474.

[8] J. Jutting, Health Insurance for the poor: Determinants of participation in Community Based Health Insurance Scheme in Rural Areas, Elsevier Ltd Paris, 2003. 
[9] I.A. Katibi, A.A. Akande, T.M. Akande, Awareness and attitude of medical practitioners in Ilorin towards National Health Insurance Scheme, Nigeria Med Pract. 43(2) (2003).

[10] O.O. Kayode, A.O. Taiwo, O. Abidemi, Users' Satisfaction with services provided under National Health Insurance Scheme in South Western Nigeria, Int. J. Trop. Ds. And Health. 4(5) (2014) 595-607.

[11] National health insurance scheme operational guidelines. National Health Insurance Scheme Abuja, Nigeria, 2005.

[12] A.N. Ofili, C.E. Ofovwe, Patients' assessment of efficiency of services at a teaching hospital in a developing country, Annals of African Medicine. 4 (2005) 150-153.

[13] K.I. Onyedibe, M.G. Goyit, N.E. Nnadi, An evaluation of the national health insurance scheme (NHIS) in Jos, a north-central Nigerian city, Global Advanced Research Journal of Microbiology. 1(1) (2012) 3-9.

[14] R.A. Sanusi, A.T. Awe, An Assessment of awareness level of National Health Insurance Scheme among Health Care Consumers in Oyo State, Nigeria, The Social Science. 4(2) (2009) 143-148.

[15] M. Shafiu, Understanding client satisfaction with a health insurance scheme in Nigeria: factors and enrollees experiences, Health Research Policy and System. 20(9) (2011) 1-8. 